\title{
Predictors of Complications after Sheath Removal Post Transfemoral Percutaneous Coronary Interventions
}

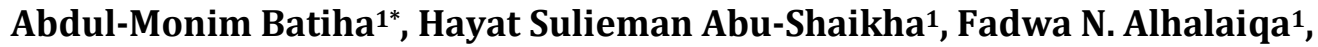 \\ Reem Ahmad Jarrad², Hasan Jamal Abu Ramadan ${ }^{3}$ \\ ${ }^{1}$ Faculty of Nursing, Philadelphia University, Amman, Jordan \\ ${ }^{2}$ Faculty of Nursing, The University of Jordan, Amman, Jordan \\ ${ }^{3}$ Saudi Red Crescent, Riyadh, Saudi Arabia \\ Email: *abatiha@philadelphia.edu.jo, habushaikha@philadelphia.edu.jo, fhalaiqa@philadelphia.edu.jo, \\ r.jarrad@ju.edu.jo, hsnjmal@yahoo.com
}

Received 26 April 2016; accepted 19 June 2016; published 22 June 2016

Copyright (C) 2016 by authors and Scientific Research Publishing Inc.

This work is licensed under the Creative Commons Attribution International License (CC BY). http://creativecommons.org/licenses/by/4.0/

(c) (i) Open Access

\begin{abstract}
Background: Complications post percutaneous coronary interventions (PCI) are more threatening than it was previously thought so that necessary measures should be taken to minimize those risks. Objective: To identify the risk factors related to patient and procedure which could be used as predictors of complications after sheath removal post PCI. Methods: The study used a prospective non-experimental correlational descriptive. Design: The sample was chosen conveniently from three different hospitals and included 118 patients who were subjected to PCI. Results: Three models were used to predict complications. In the first model, none of the baseline variables were predictive of complications. In the second model, the only type of procedure (diagnostic, stent or balloon) was predictive of complications. In the third model, compression time was found to be a risk factor and a predictor of complications after sheath removal. Conclusion: Nurses and medical professionals are in a vital position to prevent, detect and manage PCI complications at the earliest possible opportunity. It is a must to assess and categorize patients in accordance with their risk level to develop post PCI and post sheath removal complications, in order to plan management strategies to decrease the health costs and the suffering.
\end{abstract}

\section{Keywords}

Complications, Jordan, Percutaneous Coronary Interventions, Sheath Removal, Transfemoral

\footnotetext{
${ }^{*}$ Corresponding author.
}

How to cite this paper: Batiha, A.-M., Abu-Shaikha, H.S., Alhalaiqa, F.N., Jarrad, R.A. and Ramadan, H.J.A. (2016) Predictors of Complications after Sheath Removal Post Transfemoral Percutaneous Coronary Interventions. Open Journal of Nursing, 6, 497-504. http://dx.doi.org/10.4236/ojn.2016.66052 


\section{Introduction}

In recent years, percutaneous coronary interventions (PCI) have been frequently associated with different cardiac cases as a diagnostic and intervention procedure in cardiology in Jordan. Reaching homeostasis following PCI is a serious step in patient stability \& recovery [1]. PCI is also called coronary angioplasty, which is a non-surgical intervention usually done by a cardiologist to manage the conical coronary artery branches of the heart. This narrowing usually results from the presence of cholesterol plaques [2]. Restoring arterial blood flow to the heart tissue occurs after removing or opening the blocked (stenotic) segment of coronary arteries; as a consequence of this procedure, chest pain/angina, myocardial infarction (MI) and death could be prevented [3] [4].

Nurses play a critical role in PCI by monitoring vital signs, the sheath entrance site, peripheral pulses, capillary refill and chest pain [5] [6]. All these observations are done while maintaining a patient's sufficient periods of rest, providing required perfusions of drugs, and monitoring the patient for their amounts of fluid intake and output [7].

Following the procedure, most patients are discharged successfully without any complications within 24 hours [7]. However, some patients experience life-threatening complications which can turn their recovery into a disaster. These complications require nurses to use critical assessment skills, anticipate and detect any vascular problem and manage the appropriate interventions [8] [9]. Although PCI is, in general, a safe procedure, we cannot ignore the occurrence of serious complications: bleeding, hematoma, pseudoaneurysm, and arterial occlusion, which range from $1 \%-14 \%$ in reported studies [7] [8]. Also, chest pain/angina, dysrhythmia and hypotension are common complications following sheath removal [10]. These complications may lead to an increase in a patient's hospital length of stay (LOS), cost, more morbidities (e.g. MI), and even mortality [10].

Several studies investigated the risk factors that anticipate specific vascular complications. The most common reported factors were: age, sex, body weight [10]-[12]. Furthermore, the presence of chronic illnesses and the types of drugs administered during the procedure might raise the risk of vascular complications [12] [13].

Recent studies have offered evidence that bleeding, post PCI, is more dangerous than previously believed, and it is, therefore, necessary for all health care providers to take all measures to decrease it [8] [10] [14]-[16]. In a study of 10,974 PCI patients, it was mentioned that bleeding was a significant predictor of in-hospital mortality, even one year after discharge [17]. Hematoma too is considered a significant complication, even if of small size, because they delay full recovery of the patient, causing pain and discomfort [18] [19]. Additionally, pseudoaneurysm of the femoral artery carries a significant risk of morbidity and mortality [20]. The incidence of femoral artery pseudoaneurysm, after a therapeutic procedure, ranges from $0.7 \%$ to $6.25 \%$ [20]. Some studies suggested that gender could be a predictor of PCI complications. In a retrospective study of 3508 patients, they found that both female gender and low body weights are independent predictors of hematoma formation, post PCI [21].

Sheath dwelling time of five hours was statistically not a significant predictor of bleeding but dwelling equal to, or more than, seven hours was a significant predictor of PCI complications [22].

All the previous studies were conducted in western countries, none in Arabic locations. Determining the predictors of PCI complications can help screen and reinforce the standards of care that can prevent, or minimize, the occurrence of these complications [14]. Therefore, the main aim of our study was to identify the risk factors related to patient and procedure, as predictors of complications after sheath removal, post transfemoral percutaneous coronary angioplasty.

\section{Method}

\subsection{Sample}

The sample was a convenience sample of 118 patients who experienced transfemoral percutaneous coronary procedures at three hospitals in Jordan (Alesraa, Islamic and Jordan University hospital). Participants were excluded from the study if they were hemodynamically unstable after PCI.

\subsection{Design}

A prospective, non-experimental correlational descriptive study design, with comparative procedure, was used 
to investigate relationships between variables of patients who encountered complications after sheath removal post transfemoral percutaneous coronary procedures, and those of the 118 patients who did not.

\subsection{Ethical Consideration}

Ethical approval was obtained from the three settings where the study was conducted. Consent forms were obtained from participants who agreed to participate in the current study. The participant's rights were confirmed.

\subsection{Data Collection Procedure}

After approval was granted by the institutions mentioned above, the researchers contacted the heads of the patient units and health of catheterization units to receive their permission to conduct the study. The patients who met the inclusion criteria were recruited as participants. A cover letter, with an information sheet and reply envelop, was then sent to them. Patients who were interested in this study contacted the researchers who answered their questions, confirmed their rights (confidentiality, privacy, freedom to withdraw etc.) and gave their consent to be included in the current study. All data were collected by the researchers through observation of the patients and the review of their medical files, and then the relevant data were recorded on a data collection form. Data were collected at the baseline of the study, during (intra) and post the procedure.

\subsection{Instrument}

The collection form was developed by the researchers, reviewed by a cardiologist, a statistician, and senior staff nurses; slight modifications were made as a result. The questionnaire was developed to include three subgroups of factors related to sheath removal complications after transfemoral PCI:

1) Baseline variables were the first subset; the variables were the patient's age, weight, height, gender, and hematocrit level at time of hospital admission and preexisting comorbid condition (diabetes, hypertension, thrombocytopenia, and renal failure).

2) Intra-procedural variables made up the second subset of variables; they include types of procedure, the length of PCI procedure in minutes, type and units of heparin used during the procedure, use of glycoprotein IIb/IIIa inhibitors, the size of the femoral sheath and final systolic and diastolic blood pressure levels.

3) The third subset was (post-procedural variables), which included sheath indwelling time, the length of compression and hours of bed rest after sheath removal and assessment of specific complications related to sheath removal after transfemoral PCI (hematoma, bleeding, Pseudoaneurysm, dysrhythmia, hypotension, and arterial occlusion).

\subsection{Data Analysis}

Data was analyzed using the statistical package for the social sciences (SPSS), version (20). Descriptive analyses were used to describe the demographical characteristics of the participants; mean and standard deviation was used for continuous variables (e.g. age, height, weight, length of procedure per minutes); frequency and percent were used for categorical variables (e.g. gender, type of procedure, type of heparin). A chi-squared test was used to explore the relationship between two categorical variables. Additionally, an independent t-test was employed to determine if there is any difference between the two groups of patients (patient with complications and patients without complications). Logistic regression was used to predict the probability that dependent variables (complications) would occur after sheath removal post transfemoral PCI.

\section{Results}

Baseline variables for the two groups in the study: PCI patients with and without complications are shown in Table 1. The mean age of patients with complications was 59.85, comparing to 57.72 in patients without complications. Most of the participants were male (70\%), with diabetes as a pre-existing co-morbid condition. There were no significant differences between two groups in their baseline characteristics.

Table 2 summarizes intra-procedural variables. The two groups of patients differed significantly only in the use of glycoprotein IIb/IIIa inhibitor $\left(\chi^{2}=5.42 ; P=0.04\right)$. 
Table 1. Baseline variables characteristic of the 2 groups undergoing PCI.

\begin{tabular}{cccc}
\hline Characteristics & Patients with complications (n = 29) & Patients without complications (n = 89) & P \\
\hline Age, years & 59.85 & 57.72 & 0.34 \\
Gender & & & \\
Male\% (No.) & $78 \%(69)$ & $62 \%(18)$ & 0.16 \\
Female\% (No.) & $22 \%(20)$ & $38 \%(11)$ & 0.48 \\
Height, cm & 169.04 & 167.83 & 0.27 \\
Weight, kg & 82.38 & 79.14 & 0.55 \\
Hematocrit level, proportion of 1.00 & 39.59 & 39.08 & 0.23 \\
Preexisting comorbid condition & & & 0.37 \\
Diabetes, \% (No.) & $49 \%(44)$ & $62 \%(18)$ & 1 \\
Hypertension, \% (No.) & $73 \%(65)$ & $0 \%(0)$ & 0.31 \\
Thrombocytopenia, \% (No.) & $1 \%(1)$ & $10 \%(3)$ & $34 \%(10)$ \\
Renal failure, \% (No.) & $3 \%(3)$ & & \\
\hline
\end{tabular}

Table 2. Intra-procedural variables.

\begin{tabular}{|c|c|c|c|}
\hline Characteristics & $\begin{array}{c}\text { Patients with } \\
\text { complications }(n=29)\end{array}$ & $\begin{array}{c}\text { Patients without } \\
\text { complications }(n=89)\end{array}$ & $P$ value \\
\hline \multicolumn{4}{|l|}{ Type of procedure, \% (No.) } \\
\hline Diagnostic & $3 \%(1)$ & $17 \%(15)$ & \\
\hline Stent & $97 \%(28)$ & $82 \%(73)$ & 0.8 \\
\hline Balloon & 0 & $1 \%(1)$ & \\
\hline Length of procedure, (minutes) & 40.34 & 33.54 & 0.22 \\
\hline \multicolumn{4}{|l|}{ Type of heparin used, \% (No.) } \\
\hline Sodium heparin & $24 \%(7)$ & $11 \%(10)$ & 0.15 \\
\hline Unfractioned heparin & $76 \%(22)$ & $89 \%(79)$ & \\
\hline Units of heparin used & 9262 & 9189 & 0.82 \\
\hline Glycoprotein IIb/IIIa inhibitors, \% (No.) & $28 \%(8)$ & $10 \%(9)$ & $0.04^{*}$ \\
\hline \multicolumn{4}{|l|}{ Size of femoral sheath, \% (No.) } \\
\hline 6 & $93 \%(27)$ & $97 \%(86)$ & 0.77 \\
\hline 7 & $7 \%(2)$ & $3 \%(3)$ & \\
\hline Length of PCI procedure, minutes & 28.9 & 30.2 & 0.13 \\
\hline Systolic blood pressure, mean, mm Hg & 150 & 151 & 0.66 \\
\hline Diastolic blood pressure, mean, mm Hg & 84 & 82 & 0.57 \\
\hline
\end{tabular}

${ }^{*} P<0.005$.

Table 3 summarizes post-procedural variables. The 2 groups of patients differed significantly in length time of compression $(\mathrm{t}=3.42 ; P=0.002)$. A patient who developed complications received shorter compression times.

Complications were experienced by 29 (24.6\%) of the 118 patients, and these are summarized in Table 4 as follows: hematoma (44.8\%), hypotension (41.4\%), bleeding (24.1\%) and dysrhythmia (13.8\%). Major complications such as Pseudoaneurysm and loss of distal pulse did not occur. It should be noted that some patients suffered from more than one complication.

Three models were designed and examined to predict complications (Table 5). The first model tested the 6 baseline variables characteristic of the 2 groups undergoing PCI, known to be predictive of complications (age, 
Table 3. Post-procedural variables.

\begin{tabular}{ccccc}
\hline Characteristic & $\begin{array}{c}\text { Patient with } \\
\text { complications }(\mathbf{n}=\mathbf{2 9})\end{array}$ & $\begin{array}{c}\text { Patient without } \\
\text { complications (n= 89) }\end{array}$ & df & $\boldsymbol{P}$ value \\
\hline Sheath indwelling time, hours & 6.21 & 4.59 & 116 & 0.13 \\
Length of time of compression, minutes & 14.16 & 21.03 & 34.5 & $0.002^{*}$ \\
Bed rest after sheath removal, hours & 6.10 & 5.84 & 116 & 0.14 \\
\hline
\end{tabular}

${ }^{*} P<0.005$.

Table 4. Complications in the 29 patients who experience them*

\begin{tabular}{ccc}
\hline Complications & \% (No.) of patients \\
\hline Hematoma & $44.8(13)$ \\
Hypotension & $41.4(12)$ \\
Bleeding & $24.1(7)$ \\
Dysrhythmia & $13.8(4)$ \\
Pseudoaneurysm & 0 \\
Loss of distal pulse & 0 \\
\hline
\end{tabular}

*Some patients had more than 1 complication.

Table 5. Predictors of complications.

\begin{tabular}{ccccc}
\hline Model & Predictive of complications & Coefficient (B) & Exp (B) & $\boldsymbol{P}$ \\
\hline Baseline & None & & \\
Intra-procedural & Types of procedure & -13.92 & 9 & 0.000 \\
Post-procedural & Length of time of compression, minutes & -0.121 & 0.89 & 0.000 \\
\hline
\end{tabular}

gender, years, height, weight, hematocrit level, and preexisting comorbid condition). None of these variables were found to be predictors of complications.

The second model tested 9 intra-procedural variables (type of procedure, length of procedure, type of heparin used, units of heparin used, and glycoprotein IIb/IIIa inhibitors, the size of femoral sheath, the length of PCI procedure, systolic blood pressure, and diastolic blood pressure). Only types of procedure were found to be an accurate predictor of complications; the procedures being diagnostic, stent or Balloon.

The third model tested 3 post-procedural variables (sheath indwelling time, the length of compression time, and bed rest after sheath removal); the length of compression time was found to be a predictor of complications.

\section{Discussion}

The goal of this study was to ascertain if specific variables were predictive of whether complications would develop after sheath removal, post transfemoral PCI among Jordanian patients.

Removal of the Sheath and care of the patient following PCI are considered as the responsibilities of critical care nurses. Vascular complications were found in 24.6\% (29/118) of patients; a ratio similar to other reported studies [23] [24].

In this study, three models were used to predict complications. In the first model, none of the baseline variables were predictive of complications. In the second model, we tested intra-procedural variables; only types of procedure (diagnostic, stent orballoon) were predictive of complications. Of the third model, the length of compression time was found to be a risk factor; patients who developed complications received shorter compression times. These findings may rational by the hand and arm of the nurse may fatigue during the procedure which may lead to fluctuations in the pressure applied to the femoral artery. Also, it was noted that compression times vary from one nurse to another. When a complication, such as a hematoma developed, nurses increase the com- 
pression time; this makes it difficult to assess the true significance and effect of the compression time variable. To compensate for these complications, it is recommended to employ a compression time of between 15 to 20 minutes, together with adequate compression force to the femoral artery. It is also advised to consider the use of other methods of arterial vascular closure devices [24] [25].

Hamner et al. (2005) [26], found lower hematocrit levels and previous use of a closure device, were predictors of complications developed after placement of a closure device, following transfemoral PCI. Also, Dangas et al. (2001) [27] found that the use of arteriotomy closure devices was associated with a higher complication rate compared with manual compression. In our settings only manual compression was used to achieve hemostasis. Furthermore, sheath size was recognized as the most important independent predictor of femoral bleeding after PCI [28].

The current study's results are consistence with Sari et al. (2015) [29] who reported a significant negative correlation between vascular complications and diameter of the common femoral artery, and external iliac artery. Positive correlations were identified between diabetes, sheath to femoral artery ratio, procedure time, and discharge; findings that were consistent with Lange et al. (2012) [30].

Mieghem et al. (2012) [31] found that female gender and larger sheath size were associated with major vascular complications and also that combined life-threatening/disabling or major bleedings related to transfemoral transcatheter aortic valve implantation.

\subsection{Limitations}

The patient sample was chosen by using a convenience sampling method; however, we selected patients from multi-settings to enhance the generalizability of our findings. Because this study did not incorporate a long-term follow-up assessment in its design, long-term complications like lumen narrowing and local infection was not assessed. Also, some variables, like the effect of restraining extremities were not examined; future research is therefore recommended to consider these variables.

\subsection{Conclusions and Recommendations}

PCIs continue to be seen as an important method for the treatment of heart diseases and acute coronary syndromes. A multidisciplinary approach to protocol development is needed to reduce the incidence of complications. Evidence of the potential risk from this treatment provides an important base for cost-benefit studies relating to advantages of managing and predicting complications.

Finally, nursing staff and medical professionals are in a vital position to detect, prevent and manage complications at the earliest possible juncture. Nurse and health care professionals should assess patients for high risk of complications, and plan management strategies to decrease those complications.

\section{Acknowledgements}

We offer our sincere thanks to all patients who participated in this study; and to all the health care team members who helped us to complete this study.

\section{Conflict of Interest}

The authors have no competing interests.

\section{References}

[1] Wasfy, J.H., Strom, J.B., O’Brien, C., Zai, A.H., Luttrell, J., Kennedy, K.F. and Yeh, R.W. (2014) Causes of ShortTerm Readmission after Percutaneous Coronary Intervention. Circulation: Cardiovascular Interventions, 7, 97-103. http://dx.doi.org/10.1161/circinterventions.113.000988

[2] Oberhauser, J.P., Hossainy, S. and Rapoza, R.J. (2009) Design Principles and Performance of Bioresorbable Polymeric Vascular Scaffolds. EuroIntervention, 5, F15-2. http://dx.doi.org/10.4244/EIJV5IFA3

[3] Sipahi, I., Akay, M.H., Dagdelen, S., Blitz, A. and Alhan, C. (2014) Coronary Artery Bypass Grafting vs Percutaneous Coronary Intervention and Long-Term Mortality and Morbidity in Multivessel Disease: Meta-Analysis of Randomized Clinical Trials of the Arterial Grafting and Stenting Era. JAMA Internal Medicine, 174, 223-230. http://dx.doi.org/10.1001/jamainternmed.2013.12844 
[4] Alhalaiqa, F., Abu-Shbeeb, I., Batiha, A.M., Masa’Deh, R. and Amarneh, B. (2015) The Relation of Demographic Characteristics with Fatigue Levels among Coronary Heart Disease Patients: A Jordanian Study. Advanced Studies in Biology, 7, 301-322.

[5] Lewis, S.L., Dirksen, S.R., Heitkemper, M.M. and Bucher, L. (2014) Medical-Surgical Nursing: Assessment and Management of Clinical Problems, Single Volume. Elsevier Health Sciences.

[6] Saifan, A., Bashayreh, I., Batiha, A.M. and AbuRuz, M. (2015) Patient- and Family Caregiver-Related Barriers to Effective Cancer Pain Control. Pain Management Nursing, 16, 400-410. http://dx.doi.org/10.1016/j.pmn.2014.09.007

[7] Hirsch, A.T. and Duval, S. (2013) Effective Vascular Therapeutics for Critical Limb Ischemia: A Role for RegistryBased Clinical Investigation. Circulation: Cardiovascular Interventions, 6, 8-11. http://dx.doi.org/10.1161/circinterventions.113.000127

[8] Chhatriwalla, A.K., Amin, A.P., Kennedy, K.F., House, J.A., Cohen, D.J., Rao, S.V., National Cardiovascular Data Registry (2013) Association between Bleeding Events and In-Hospital Mortality after Percutaneous Coronary Intervention. JAMA, 309, 1022-1029. http://dx.doi.org/10.1001/jama.2013.1556

[9] Batiha, A.M., Obead, K.A., Alhalaiqa, F.N., Kawafha, M.M., El-Razek, A.A., Albashtawy, M., Saifan, A., Ruz, M.E.A. and Al Ewaidat, H. (2015) Quality of Life and Fatigue among Jordanian Cancer Patients. Iranian Journal of Public Health, 44, 1704.

[10] Burzotta, F., Mariani, L., Trani, C., Coluccia, V., Brancati, M.F., Porto, I. and Mazzari, M.A. (2013) Management and Timing of Access-Site Vascular Complications Occurring after Trans-Radial Percutaneous Coronary Procedures. International Journal of Cardiology, 167, 1973-1978. http://dx.doi.org/10.1016/j.ijcard.2012.05.017

[11] Hassan, A.K., Hasan-Ali, H., Demetry, S.R., Refaat, R. and Ali, A.S. (2015) Early Sheath Removal after Percutaneous Coronary Intervention Using Assiut Femoral Compression Device Is Feasible and Safe. Results of a Randomized Controlled Trial. The Egyptian Heart Journal, 67, 69-77. http://dx.doi.org/10.1016/j.ehj.2014.10.003

[12] Burzotta, F., De Vita, M., Lefevre, T., Tommasino, A., Louvard, Y. and Trani, C. (2014) Radial Approach for Percutaneous Coronary Interventions on Chronic Total Occlusions: Technical Issues and Data Review. Catheterization and Cardiovascular Interventions, 83, 47-57. http://dx.doi.org/10.1002/ccd.25118

[13] Alhalaiqa, F., Masa'Deh, R., Batiha, A.M. and Deane, K. (2014) Validity of Arabic Version of Beliefs about Medication Questionnaire. Clinical Nursing Research, 24, 539-555.

[14] Rao, S.V., Tremmel, J.A., Gilchrist, I.C., Shah, P.B., Gulati, R., Shroff, A.R. and Sanghvi, K. (2014) Best Practices for Transradial Angiography and Intervention: A Consensus Statement from the Society for Cardiovascular Angiography and Intervention’s Transradial Working Group. Catheterization and Cardiovascular Interventions, 83, 228-236. http://dx.doi.org/10.1002/ccd.25209

[15] Alkhawaldeh, A., Al Omari, O., Al Bashtawy, M., Aljezawi, M., Suliman, M., Holm, M., Qaddumi, J., Batiha, A., Alhalaiqa, F. and Saifan, A. (2016) Long-Term Conditions in Older Adults Using Primary Care Services. Primary Health Care, 26, 31-35. http://dx.doi.org/10.7748/phc.26.2.31.s23

[16] Mu'taz, M.D., Alrimawi, I., Saifan, A.R. and Batiha, A.M. (2016) Hand Hygiene Knowledge, Practices and Attitudes among Nurses and Physicians. Health, 8, 456-462. http://dx.doi.org/10.4236/health.2016.85048

[17] Kinnaird, T.D., Stabile, E., Mintz, G.S., Lee, C.W., Canos, D.A., Gevorkian, N. and Weissman, N.J. (2003) Incidence, Predictors, and Prognostic Implications of Bleeding and Blood Transfusion Following Percutaneous Coronary Interventions. The American Journal of Cardiology, 92, 930-935. http://dx.doi.org/10.1016/S0002-9149(03)00972-X

[18] Sanidas, E.L.I.A.S., Buysschaert, I. and van Langenhove, G. (2014) Iatrogenic Left Main Coronary Artery Dissection and Intramural Hematoma Caused by Diagnostic Transradial Cardiac Catheterization. Hellenic Journal Of Cardiology, 55, 65-69.

[19] Batiha, A.-M. (2014) Pain Management Barriers in Critical Care Units: A Qualitative Study. International Journal of Advanced Nursing Studies, 3, 1-5.

[20] Dzijan-Horn, M., Langwieser, N., Groha, P., Bradaric, C., Linhardt, M., Böttiger, C., Hadamitzky, M., et al. (2014) Safety and Efficacy of a Potential Treatment Algorithm by Using Manual Compression Repair and Ultrasound-Guided Thrombin Injection for the Management of Iatrogenic Femoral Artery Pseudoaneurysm in a Large Patient Cohort. Circulation: Cardiovascular Interventions, 7, 207-215. http://dx.doi.org/10.1161/circinterventions.113.000836

[21] Farouque, H.O., Tremmel, J.A., Shabari, F.R., Aggarwal, M., Fearon, W.F., Ng, M.K. and Lee, D.P. (2005) Risk Factors for the Development of Retroperitoneal Hematoma after Percutaneous Coronary Intervention in the Era of Glycoprotein IIb/IIIa Inhibitors and Vascular Closure Devices. Journal of the American College of Cardiology, 45, 363-368. http://dx.doi.org/10.1016/j.jacc.2004.10.042

[22] Galli, A. and Palatnik, A. (2005) Ask the Experts. Critical Care Nurse, 25, 88-95.

[23] Sulzbach-Hoke, L.M., Ratcliffe, S.J., Kimmel, S.E., Kolansky, D.M. and Polomano, R. (2010) Predictors of Complications Following Sheath Removal with Percutaneous Coronary Intervention. Journal of Cardiovascular Nursing, 25, 
E1-E8. http://dx.doi.org/10.1097/JCN.0b013e3181c83f4b

[24] Merriweather, N. and Sulzbach-Hoke, L.M. (2012) Managing Risk of Complications at Femoral Vascular Access Sites in Percutaneous Coronary Intervention. Critical Care Nurse, 32, 16-29. http://dx.doi.org/10.4037/ccn2012123

[25] Obead, K.A., Batiha, A.M., Al-Jauissy, M.S., Alhalaiqa, F. and AlBashtawy, M. (2014) Impact of Radiotherapy Treatment on Jordanian Cancer Patients' Quality of Life and Fatigue. International Journal of Advanced Nursing Studies, 3, 6-12.

[26] Hamner, J.B., Dubois, E.J. and Rice, T.P. (2005) Predictors of Complications Associated with Closure Devices after Transfemoral Percutaneous Coronary Procedures. Critical Care Nurse, 25, 30-37.

[27] Dangas, G., Mehran, R., Kokolis, S., Feldman, D., Satler, L.F., Pichard, A.D., Kent, K.M., Lansky, A.J., Stone, G.W. and Leon, M.B.(2001) Vascular Complications after Percutaneous Coronary Interventions Following Hemostasis with Manual Compression versus Arteriotomy Closure Devices. Journal of the American College of Cardiology, 38, 638641. http://dx.doi.org/10.1016/S0735-1097(01)01449-8

[28] Doyle, B.J., Ting, H.H., Bell, M.R., Lennon, R.J., Mathew, V., Singh, M., Holmes, D.R. and Rihal, C.S. (2008) Major Femoral Bleeding Complications after Percutaneous Coronary Intervention: Incidence, Predictors, and Impact on Long-Term Survival among 17,901 Patients Treated at the Mayo Clinic from 1994 to 2005. Jacc: Cardiovascular Interventions, 1, 202-209. http://dx.doi.org/10.1016/j.jcin.2007.12.006

[29] Sari, C., Ayhan, H., Aslan, A. N., Durmaz, T., Keleş, T., Baştuğ, S., Bozkurt, E., et al. (2015) Predictors and Incidence of Access Site Complications in Transcatheter Aortic Valve Implantation with the Use of New Delivery Systems. Perfusion, 30, 666-674. http://dx.doi.org/10.1177/0267659115578002

[30] Lange, R., Bleiziffer, S., Mazzitelli, D., Elhmidi, Y., Opitz, A., Krane, M., Schreiber, C., et al. (2012) Improvements in Transcatheter Aortic Valve Implantation Outcomes in Lower Surgical Risk Patients: A Glimpse into the Future. Journal of the American College of Cardiology, 59, 280-287. http://dx.doi.org/10.1016/j.jacc.2011.10.868

[31] Van Mieghem, N.M., Tchetche, D., Chieffo, A., Dumonteil, N., Messika-Zeitoun, D., van der Boon, R.A., de Jaegere, P.T. (2012) Incidence, Predictors, and Implications of Access Site Complications with Transfemoral Transcatheter Aortic Valve Implantation. The American Journal of Cardiology, 110, 1361-1367. http://dx.doi.org/10.1016/j.amjcard.2012.06.042 